\title{
MUDANÇAS NA SINUOSIDADE NO TRECHO URBANO DO CÓRREGO TAMANDUÁ EM APARECIDA DE GOIÂNIA (GO): RESULTADOS QUALITATIVOS PRELIMINARES
}

\author{
Jakeline Alves Silva $^{(\mathrm{a})}$, Ludmilla Lima Amaral ${ }^{(\mathrm{b})}$,Isabela Braichi Pôssas $^{(\mathrm{c})}$, Luis Felipe Soares \\ Cherem ${ }^{(\mathrm{d})}$ \\ (a) Instituto de Estudos Socioambientais, Universidade Federal de Goiás, jakelineambiental@ @otmail.com \\ (b) Instituto de Estudos Socioambientais, Universidade Federal de Goiás, ludylima_04@ hotmail.com \\ (c) Instituto de Estudos Socioambientais, Universidade Federal de Goiás, isabelabraichi@ gmail.com

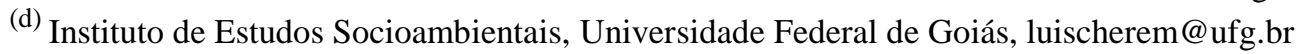

Eixo: Uso e ocupação das terras e legislação ambiental

\begin{abstract}
Resumo
A bacia do Córrego Tamanduá, inserida integralmente na malha urbana de Aparecida de Goiânia (GO), foi caracterizada pela impermeabilização do solo em razão da ocupação e do asfaltamento das vias entre 2002 e 2012. Desta forma, este trabalho teve como objetivo analisar a relação entre as mudanças na sinuosidade do canal do Córrego Tamanduá e a impermeabilização do solo em sua bacia hidrográfica. O mapeamento da sinuosidade do canal e da impermeabilização da sub-bacia foi realizado com base na análise de imagens de satélite de alta resolução (Digital Globe). Os resultados demostraram uma alteração no canal retilíneo para muito retilíneo em trecho do alto-médio curso, e de um padrão retilíneo para mito sinuoso no baixo curso. A impermeabilização do solo, especialmente nas áreas da planície aluvial, se constitui como um dos possíveis fatores responsáveis pela alteração do canal.
\end{abstract}

Palavras chave: Sinuosidade. Canal fluvial. Expansão da malha urbana.

\section{Introdução}

O processo de expansão da mancha urbana do município de Aparecida de Goiânia, nas últimas décadas sofreu uma expansão intensa caracterizada pelo parcelamento de chácaras, formando extensos vazios surgindo próximos ao limite municipal de Goiânia. A instalação de inúmeras indústrias atraídas por incentivos fiscais tem gerado grande crescimento econômico, configurando a conurbação e sérios conflitos socioambientais. O crescimento acelerado e a especulação imobiliária fazem com que a superfície do espaço urbano torne-se cada vez mais impermeabilizada, fazendo com que o fluxo d'água, principalmente nos períodos chuvosos, não infiltre no solo e concentre-se em determinados locais, ocasionando enchentes e sobrecarregando a vazão dos cursos d'água que drenam as áreas urbanizadas, sendo a drenagem urbana uma das questões mais complexas no planejamento e ordenamento da Região Metropolitana de Goiânia (FARIA, 2007). Em Aparecida de Goiânia, a ocupação desordenada intensificou-se após a promulgação, em Goiânia, da Lei Municipal no 4.526 de 1972, que disciplinando o parcelamento do solo da capital, 


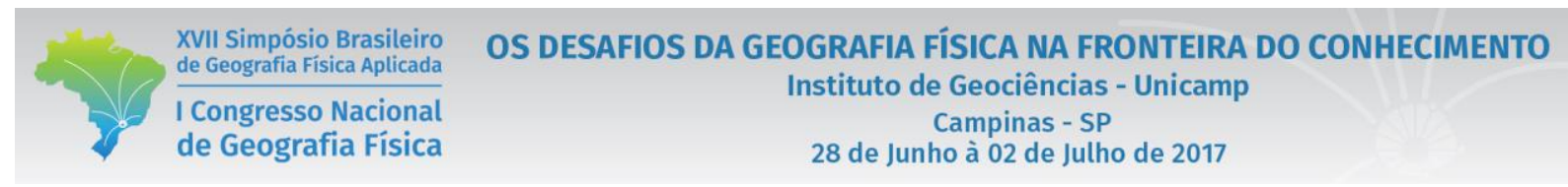

impediu a instalação de novos loteamentos que não tivessem infraestrutura urbana. Essas exigências e a flexibilidade de regulação urbana em Aparecida de Goiânia fizeram com que o capital especulativo imobiliário passasse a lotear grande parte do município.

Os impactos urbanos e ambientais consequentes da ocupação sem infraestrutura condicionam a dinâmica e a morfologia em todo o vale fluvial, marcadamente, no canal principal: acelerando e aumentando o volume de água no escoamento superficial, intensificando as vazões extremas e aumentando a disponibilidade de carga disponível para transporte, durante eventos de chuva (GILVEAR, 2003; GREGORY, 2006). Assim, a expansão da mancha urbana tem um papel central na mudança das características dos vales e seus canais fluviais e, nos municípios de regiões metropolitanas brasileiras, não é diferente (GUERRA, CUNHA, 2006; CUNHA, 2010; RODRIGUES, 2011). Em Aparecida de Goiânia (GO) as alterações nas características dos canais fluviais foram marcantes, aumentando o volume de sedimento acumulado no canal, intensificando as vazões extremas e modificando a morfologia dos canais e seu padrão (retilíneo, sinuoso, meandrante). Nesse sentido, é analisada a relação entre o aumento da impermeabilização do solo e a mudança nos padrões de canal principal do Córrego do Tamanduá, uma bacia hidrográfica que drena integralmente dentro da malha urbana (Figura 1).
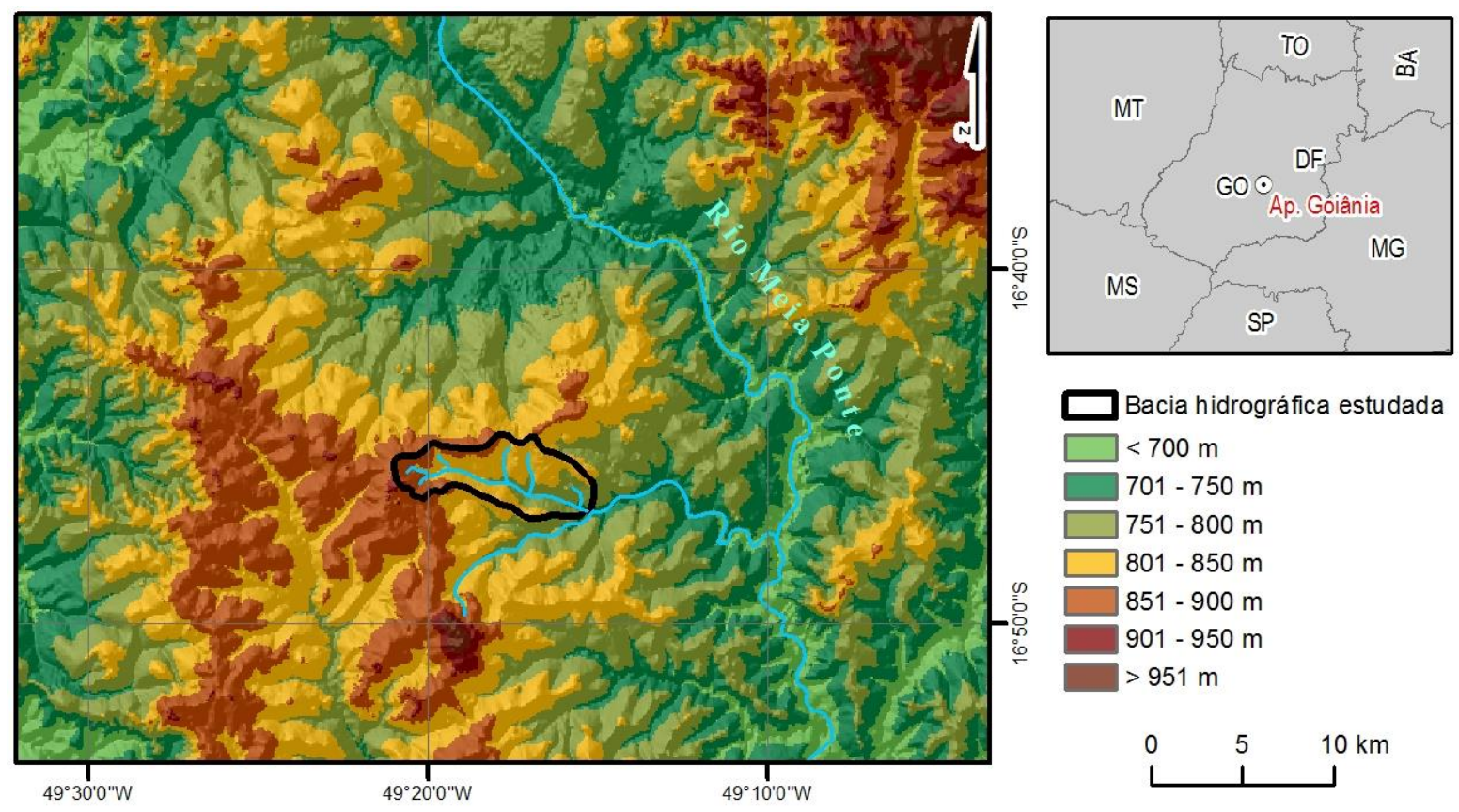

Figura 1 - Rede de drenagem e interflúvio da bacia hidrográfica do Córrego do Santo Antônio com identificação do Córrego. do Tamanduá - interflúvio em preto (esquerda) e localização do município de Aparecida de Goiânia (direita superior). Projeção geográfica, datum horizontal: SAD69; altimetria: SRTM 3'-arc, sombreado. 


\section{Materiais e métodos}

Os dados obtidos de imagens de satélite de alta resolução (Digital Globe) foram tratados em ambiente digital (SIG), onde a impermeabilização foi classificada de acordo com a proposta de COSTA et al. (2005): em pouco permeável - baixa permeabilidade ( $<33 \%$ de cobertura urbana em quarteirão/quadra), moderadamente permeável - média permeabilidade $(33 \%<x<66 \%)$, permeável - alta permeabilidade $(66 \%<x<99 \%)$ e muito permeável - não ocupada (100\% permeável, sem ocupação alguma). O canal do Córrego do Tamanduá foi mapeado para os dois períodos. Por fim, os dados foram comparados e sua variação espacial e temporal foi analisada.

\section{Resultados e Discussão}

Em 2002, a classe de baixa permeabilidade já ocupava o extremo alto trecho da bacia do Córrego Tamanduá e também vertentes da margem esquerda do médio trecho da bacia (Figura 2). A classe de média permeabilidade ocupava algumas vertentes na margem esquerda no médio curso, as vertentes da margem direita do médio curso e o interflúvio da margem direita no baixo curso da bacia. A classe de alta permeabilidade ocupava as vertentes do alto-médio curso da bacia e as planícies do Córrego Tamanduá e seus afluentes de margem esquerda (Figura 2). A classe 100\% permeável ocupava trechos de vertentes no médio curso, e o baixo curso da bacia. Em comparação com 2012, toda a área de média permeabilidade permeável foi convertida para área de baixa permeabilidade (Figura 2). Já as áreas $100 \%$ permeáveis e de alta permeabilidade ocupavam as mesmas áreas, exceto um novo loteamento que ocupou uma vertente na margem esquerda no médio curso.

Observa-se que em 2002, as cabeceiras do alto trecho da bacia tinham baixa permeabilidade, enquanto as cabeceiras dos afluentes de margem esquerda ainda estavam entre alta e média permeabilidade. Em 2012, os afluentes do médio curso do Córrego do Tamanduá foram convertidos para baixa permeabilidade. Observa-se que em 2012, portanto, todas as cabeceiras já eram pouco permeáveis, potencializando o escoamento superficial em eventos de chuvas, possibilitando a ocorrência de inundações e enchentes, em uma drenagem com maior volume de água e maior energia. As encostas do lado sul da bacia (margem direita), em geral, mantiveram seu grau de permeabilidade, exceto por um trecho de $2 \mathrm{~km}$ no médio trecho da bacia. 

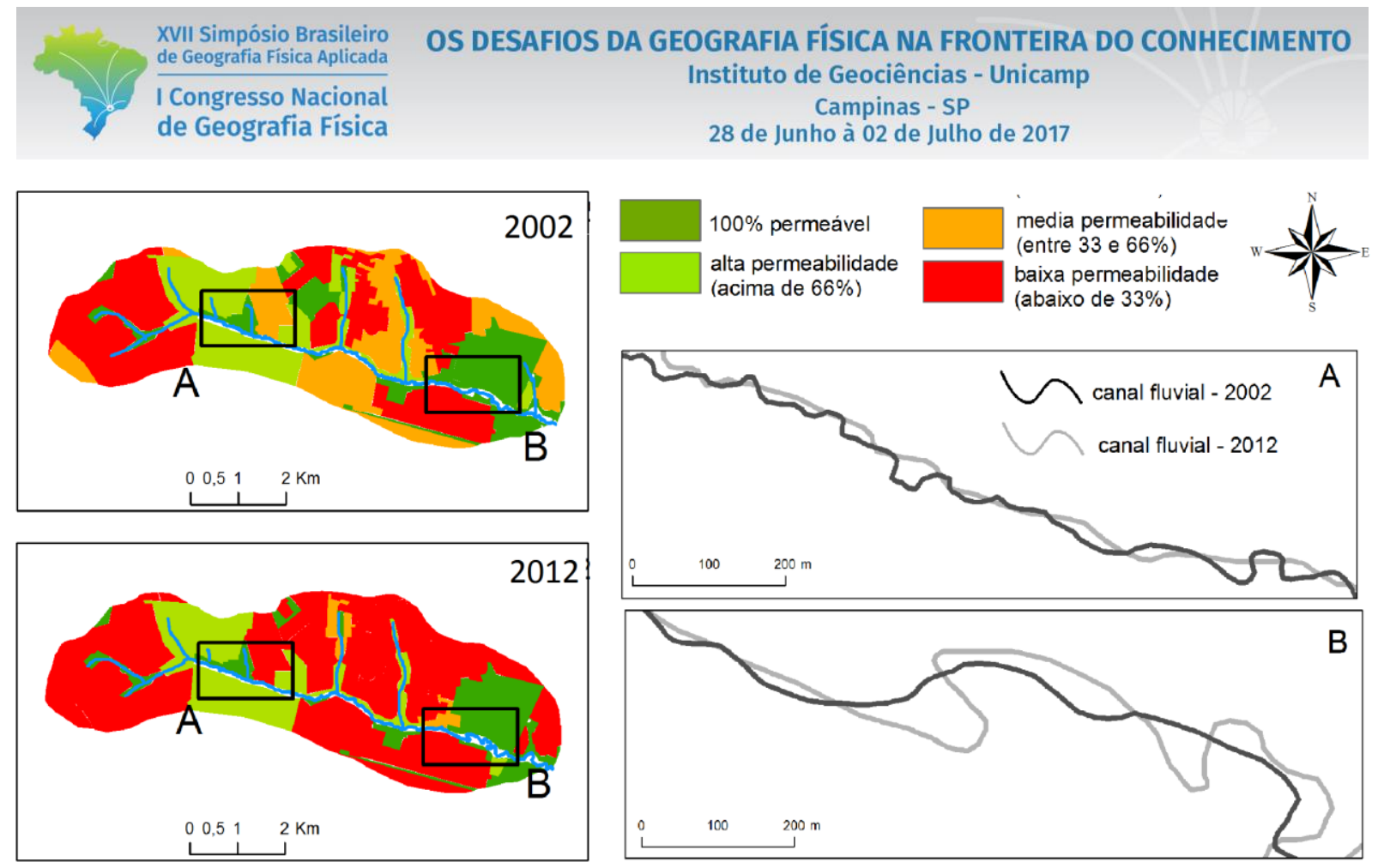

Figura 2 - Mapeamento da permeabilização da bacia do Córrego Tamanduá em 2002 (canto superior esquerdo) e em 2012 (canto inferior esquerdo). Mapeamento do alto médio curso do canal do Córrego Tamanduá (canto superior direito) e do baixo curso do canal do Córreto Tamanduá (canto inferior direito).

O alto médio trecho do canal do Córrego do Tamanduá apresentou índice de sinuosidade de 14,16\%, em 2002, e 1,21\% em 2012 (Figura 2A), mantendo a classificação em muito reto (Christofoletti, 1980), mas reduzindo-se em 12,95\%. O baixo trecho, por sua vez, apresentou índice de sinuosidade de 19,59\%, em 2002, e 67,73\% em 2012 (Figura 2B), alterando sua sinuosidade de reto para muito sinuoso (Christofoletti, 1980), um incremento de $48,14 \%$ na sinuosidade.

Ao analisar os dados do canal e da permeabilidade da bacia em conjunto, verifica-se que nos trechos alto e médio, a impermeabilização das vertentes e dos afluentes aumentou o volume de água do escoamento superficial que chega ao Córrego do Tamanduá nos eventos de chuvas extremos. Entre os dois anos, a sinuosidade desse trecho foi reduzida em 10 vezes. No baixo trecho, a alta permeabilidade associada a não ocupação da planície permitiu que o canal aumenta-se sua sinuosidade em 3,3 vezes, tornando-se um canal muito sinuoso.

\section{Considerações Finais}

Na bacia hidrográfica estudada, verificou-se que há concomitância/simultaneidade entre o aumento da impermeabilização dado pelo aumento da mancha urbana e a redução da sinuosidade em 10 vezes e que em um trecho onde a permeabilidade foi mantida em 100\%, o canal aumentou sua sinuosidade em 3,3 vezes. Por essas alterações terem sido observadas em um mesmo canal, é necessário o entendimento da 
dinâmica fluvial ao longo do ano hidrológico, pois, em canais fluviais, os processos desenvolvidos à montante influenciam aqueles de trechos a jusante. Os resultados devem ser comparados com o tipo de ocupação de solo dentro da planície e do leito maior para os anos estudados para avaliar sua relação.

\section{Agradecimentos}

Os autores agradecem à equipe do Laboratório de Geomorfologia e Pedologia e Geografia Física LABOGEF da Universidade Federal de Goiás pelo apoio técnico.

\section{Bibliografia}

CASTRO, W.S ZANCOPÉ, M.H.C. Migração do Canal na Planície Fluvial do Rio Claro - Bacia do Araguaia, Goiás, Brasil. Revista Geonorte, Edição Especial 4, v.10, n.1, 2014. p.343-349.

COSTA, H. B., ROSSI, M., COELHO, R. M. Mapa de impermeabilização do solo da bacia do Ribeirão das Anhumas, Campinas-SP. Simpósio Brasileiro de Geografia Física Aplicada, 11, São Paulo: USP, 2005. p. 876895.

CUNHA, S. B. Morfologia dos canais urbanos nos trópicos úmidos: a experiência no Brasil. In: II Seminário Iberoamericano de Geografía Física. Universidade de Coimbra: Coimbra, 2010. 14p.

CUNHA, S. B. Rios Desnaturalizados. In: BARBOSA, J.L.; LIMONAD, E. (Org.) Ordenamento Territorial e Ambiental. UFF, Editora UFF. Niterói, 2012. p. 171 - 191.

FARIA, Karla. ANJOS, Celma. ROMA, Renata. Diagnóstico, Ambiental preliminar do Córrego Baliza: Agência Municipal de Meio Ambiente - Goiânia, 2007.

GILVEAR, D.; BRYANT, R. Analysis of Aerial Photography and Other Remotely Sensed Data. In: KONDOLF, G. M. e PIÉGAY, H. Tools in fluvial geomorphology. New York: Wiley, 2003. p. 135-70.

GREGORY, K. J. The human role in changing river channels. Geomorphology, v.79, n. 3-4, 2006. p. 172-191.

GUERRA, A.J.T. \& CUNHA, S.B. (Org.) Impactos ambientais urbanos do Brasil ambientais urbanos do Brasil. 4.ed. Rio de Janeiro: Bertrand Brasil, 2006.

SILVA, D.A. et al. Carta de risco Aparecida de Goiânia. Goiânia: ViaSAT/Prefeitura Municipal de Aparecida, 2012. 246p. 


$\begin{aligned} & \text { XVII Simpósio Brasileiro } \\ & \text { de Geografia Fisica Aplicada }\end{aligned}$
$\begin{aligned} & \text { I Congresso Nacional } \\ & \text { de Geografia Física }\end{aligned}$

RODRIGUES, Cleide. Avaliação do impacto humano da urbanização em sistemas hidro-geomorfológicos. Desenvolvimento e aplicação de metodologia na grande São Paulo. Revista do Departamento de Geografia, São Paulo, v. 20, 2011. p. 111-125. 